\title{
A Novel Magnetic Voltage Regulator for Self-Regulated Self-Excited Three-Phase Synchronous Generator
}

\author{
G.A. Ghoneem \\ Dept. of Elect. Eng. , Faculty of Eng. \\ Menoufiya University, Shebien El-Kom, Egypt.
}

\begin{abstract}
This paper presents a magnetic voltage regulator (MVR) as a new technique for sensitive voltage control of three phase self-excited synchronous generator; The proposed MVR is a passive magnetic element, consisting of a magnetic core with three limbs. Three identical main coils (MC) are mounted on the middle limb and they are connected in series with the generator lines, with special arrangements. The second limb carries a regulating coil (RC), which is connected to a variable inductive reactance for orienting the flux into the core limbs. An exciting coil (EC) is mounted on the third limb, which feeds the generator field winding through a bridge rectifier. The MVR offers a versatile range of regulating characteristics. It has small size, simple and reliable and exhibit low impedance and low energy loss.

The equivalent circuit model representing the system is proposed. Equations describing the system are developed and computed, illustrating the theoretical performance. The experimental set up is implemented to obtain the measured results at no-load and load operation. Calculated and measured results at different values of load are presented, where good, agreement has been achieved.
\end{abstract}

Manuscript received from Dr. G.A . GHONEEM

on : $29 / 7 / 2000$

Accepted on : $9 / 9 / 2000$

Engineering Research Bulletin, Vol 23,No 4, 2000 Minufiya University, Faculty of Engineering, Shebien EI-Kom, Egypt, ISSN 1110-1180 


\section{Introduction}

The self-excited synchronous or induction generator is becoming popular as a source of power supply in isolated and remote areas. Such generators are capable of generating electric power from unconventional energy sources like wind power. Comparing with induction generator, the synchronous generator has the advantage of supplying its own magnetizing current but it is more expensive due to the use of separate exciting system. So, many techniques have been made in the development of brushless self-excited synchronous generators [1-14] .The self-excited single phase synchronous generators have been carried out [1-6], where rotor excitation is obtained by process of induction and rectification. Self- excitation has been achieved by one or two diodes connected to the rotor windings. The stator has two shifted windings; loading and capacitor windings .The brushless self- excited three phase synchronous generators have been investigated and analyzed [7-13]. The construction of such generators seems to be simple due to the absence of the brushes. The series excitation technique has been applied for the three-phase synchronous motor [14], where excitation has been achieved by the series connection of stator windings to the field winding via an exciting transformer and rectifier bridge. In generating mode [15] self-excitation achieves voltage stabilization since the field current varies with the generator load current. Good voltage regulation has been obtained, comparing with the conventional selfexcited synchronous generator.

It is important to maintain the terminal voltage of synchronous generator constant against load. To achieve that, many methods have been proposed. Each has its advantages and disadvantages. One of these methods; a step down voltage transformer is connected at the generator terminals. The secondary winding of this transformer feeds the generator field winding through a rectifier bridge. Additional series windings are also wound on the transformer core and connected with the generator lines. The flux produced from these series windings regulates the generator excitation against load current. However this method is complicated and the terminal voltage is regulated in narrow range of loading. Recently, the reciprocated flux voltage regulator, based on the flux linkage orientation has been presented [16]. Where orienting the flux in the core controls the output voltage over a wide range of load.

In this work, the MVR as a new technique for self-regulated self-excited three phase synchronous generator is proposed to maintain the generator terminal voltage constant with variable load. It is simple in construction and reliable in operation. Moreover the terminal voltage is controlled over a wide range of loads. Operation of the system is analyzed and tested in two modes; with and without capacitor at the generator terminals. The external characteristics of the generator are obtained, showing the different levels of compound characteristics (over, under, flat). For sensitive voltage regulation, a variable inductive reactance is used across the regulating coil of the MVR. This 
controls and orients the flux in the core. Consequently, a versatile range of voltage control can be achieved.

\section{Description of the MVR}

The proposed MVR connected with a three phase synchronous generator and load is shown in Fig.1. It consists of a magnetic core with three limbs. The middle limb carries three main coils (MC), with equal turns. These coils are inserted in series with the terminals between the generator and load, with special arrangement. One of the generator lines must be connected in opposite direction to its corresponding coil. This produces a flux in the middle limb equals twice the flux of any generator phase .If the circuits of the two coils EC and $\mathrm{RC}$ are opened, the flux in the middle limb is equally divided between the other two limbs. The second limb has a regulating coil, which may be short circuited or connected to a variable inductance (L) for wide rang of control .The third limb carries the exciting coil (EC), which feeds the generator field winding through a bridge rectifier. It can be noticed that, increasing the load current increases the flux in the middle limb, which consequently increases the flux in the exiting coil limb. Then the induced e.m.f in the EC increases, leading to a higher field current. If the regulating coil circuit is closed, the flux of the regulating coil limb can be oriented into the exciting coil limb. This increases the induced e.m.f of the EC and then increases the field current to a higher value. Connecting the inductance $L$ leads to adjusting the level of the field current increasing.

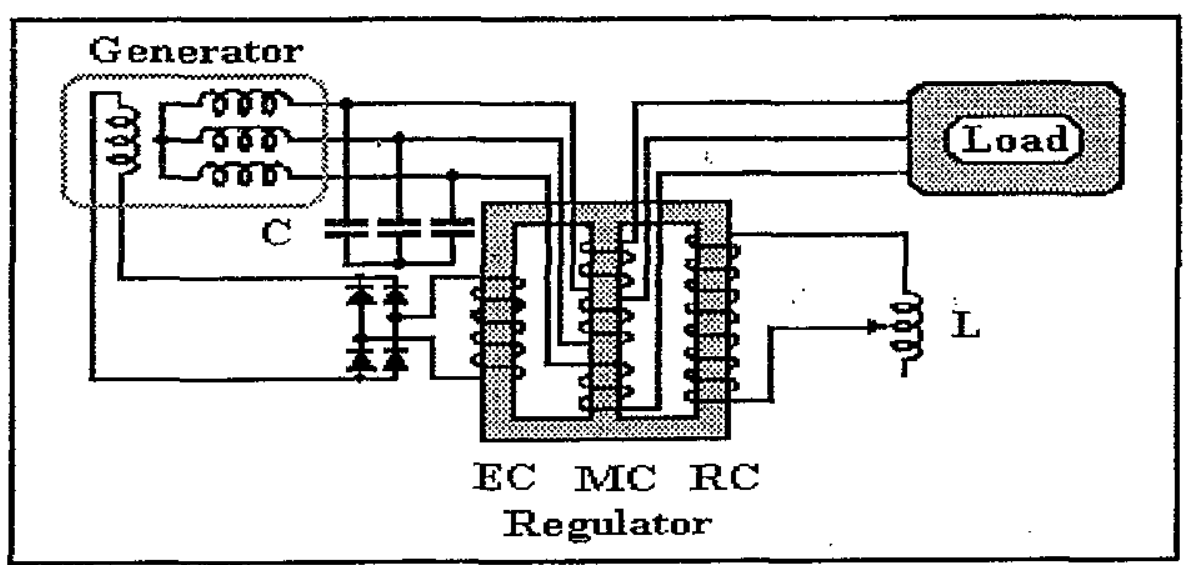

Fig.1 The magnetic voltage regulator connected with the generator 


\section{System Operation}

\subsection{Without capacitor}

In this mode the generator must be loaded for building-up voltage. Depending on the generator residual flux and speed, a small-generated e.m.f can be induced in the generator phases. When a load is connected to the generator, the flux increases and so does the generated voltage. This is because the excitation current depends on the load current. Also adjusting the variable inductance $L$ can control the generated voltage. However this mode of operation is obviously suitable for special application, such as voltage booster.

\subsection{With capacitor at the generator terminals}

At no-load, the generator operates as a capacitor self-excited synchronous generator. The value of the no-load voltage depends on the magnetization curve and the capacitive reactance value. When a load is added, The field current increases which in turn increases the generated voltage and so on. This process terminates at a finite voltage, due to the nonlinear behavior of the magnetic circuit. By adjusting the value of inductance $L$, the compound characteristics (over, flat and under) can be achieved. This mode of operation is more suitable for loads requiring reasonable good voltage regulation

\section{The Equivalent Circuit Model}

The phase equivalent circuit of Fig. 2 is proposed to obtain the mathematical analysis. The generator is represented by the induced e.m.f (Ea). The armature resistance, leakage reactance and magnetizing reactance are represented by $R_{a}$, $X_{\mathrm{La}}, \mathrm{X}_{\mathrm{ma}}$ respectively. A capacitor $\mathrm{C}$ is connected at the generator terminals for building-up voltage at no- load. $\mathrm{R}_{1}, \mathrm{X}_{\mathrm{Ll}}$ represent the resistance and leakage reactance of the MC of the MVR. Since the total flux in the middle limb is twice the flux produced from any generator phase current, the magnetizing reactance of the $\mathrm{MC}$ becomes $\left(2 \mathrm{X}_{\mathrm{m}}\right)$. This reactance may be equally divided to two values; one for $\mathrm{EC}$ circuit and the other for the RC circuit as shown in Fig.2.

The referred e.m.f.'s produced due to the mutual coupling between the two coils $\mathrm{EC}$ and $\mathrm{RC}$ are represented by $\mathrm{E}_{23}^{\prime}$ and $\mathrm{E}_{32}$. Where;

$$
\mathrm{E}_{23}^{\prime}=\omega \mathrm{M}_{23}^{\prime} \dot{I}_{3}^{\prime} \text { and } \quad \mathrm{E}_{32}=\omega \mathrm{M}_{32} \mathrm{I}_{2}
$$

Where; $\omega$ is the angular frequency and $M_{23}$ and $M_{32}$ are the referred mutual inductance between the two coils. The parameters $R_{3}, X_{L 3}$ and $X_{m 3}^{\prime}$ represent the resistance, leakage reactance and magnetizing reactance of the $\mathrm{RC}$ circuit referred to the $\mathrm{MC}$ circuit. $\mathrm{R}_{2}^{\prime}, X_{12}^{\prime}$ and $\mathrm{X}_{m 2}^{\prime}$ represent the resistance and leakage reactance and magnetizing reactance of the EC referred to the $\mathrm{MC}$ circuit. $\mathrm{R}_{\mathrm{r}}$ represents the field winding resistance referred to the $\mathrm{MC}$ circuit 


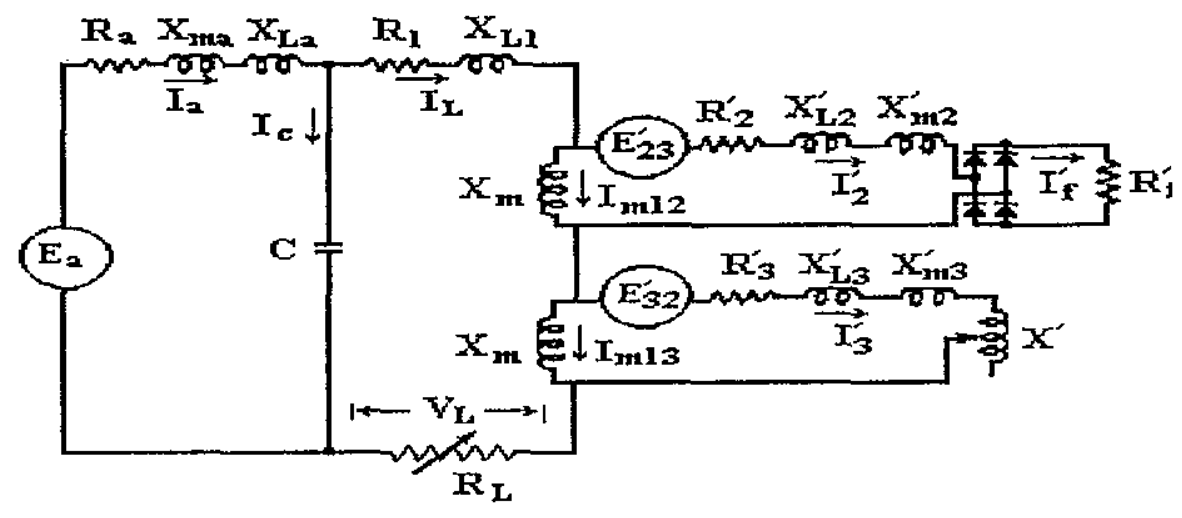

Fig.2 The equivalent circuit per phase

\section{Mathematical Analysis}

The theoretical performance of the generator operated under the MVR is obtained as follows;

1- the magnetization and synchronous reactance curves are measured as shown in Figs. 3 and 4 . The obtained results are fitted and represented by the following equations:

$$
\begin{gathered}
E_{a}=9.457+132.691 I_{f}-17.175 \mathrm{I}_{f}^{2}+0.295 \mathrm{I}_{\mathrm{f}}^{3} \\
X_{S}=224.3+28.678 \mathrm{I}_{\mathrm{f}}-33.557 \mathrm{I}_{\mathrm{f}}^{2}+4.632 \mathrm{I}_{\mathrm{f}}^{3}
\end{gathered}
$$

Where; $E_{\mathrm{a}}$ the no-load induced e.m.f

$X_{\mathrm{s}}$ the synchronous reactance $=\left(X_{\mathrm{ma}}+\mathrm{X}_{\mathrm{La}}\right)$

$I_{f}$ the field winding current

2- the no-load operating point is defined depending on the capacitive reactance value $\left(X_{c}\right)$, generator speed and the magnetization curve. At $X_{S}=$ $X_{c}$, the current $I_{f}$ can be defined from equation (2) and then the no-load induced e.m. $f$ is obtained from equation (1).

3- when the generator is loaded by a resistance $R_{L}$; the equations representing the system are derived as;

$$
\begin{aligned}
& \mathrm{E}_{\mathrm{a}}=\left(Z_{\mathrm{a}}+\mathrm{X}_{\mathrm{c}}\right) \mathrm{I}_{\mathrm{a}}-\mathrm{X}_{\mathrm{c}} \mathrm{I}_{\mathrm{L}} \\
& 0=-X_{\mathrm{c}} \mathrm{I}_{\mathrm{a}}+\left(\mathrm{X}_{\mathrm{c}}+Z_{1}+\mathrm{R}_{\mathrm{L}}+2 \mathrm{X}_{\mathrm{m}}\right) \mathrm{I}_{\mathrm{l}}-\left(\mathrm{I}_{2}+\dot{I}_{3}\right) X_{\mathrm{m}}
\end{aligned}
$$




$$
\begin{aligned}
0 & =-X_{m} I_{L}+\left(X_{m}+Z_{2}^{\prime}+X_{b} R_{f}^{\prime}\right) I_{2}^{\prime}-X_{23}^{\prime} I_{3}^{\prime} \\
0 & =-X_{m} I_{L}+\left(X_{m}+Z_{3}^{\prime}+X^{\prime}\right) I_{3}-X_{32}^{\prime} I_{2}^{\prime} \\
I_{c} & =I_{a}-I_{L} \\
I_{m 12} & =I_{L}-I_{2}^{\prime} \\
I_{m 13} & =I_{L}-I_{3}^{\prime} \\
I_{f} & =k_{b} I_{2}^{\prime}
\end{aligned}
$$

Where:

$$
\begin{aligned}
Z_{\mathrm{a}} & =\mathrm{R}_{\mathrm{a}}+\mathrm{j}\left(\mathrm{X}_{\mathrm{La}}+\mathrm{X}_{\mathrm{ma}}\right) \\
\mathrm{X}_{\mathrm{c}} & =-\mathrm{j}(1 / \omega \mathrm{C}) \\
Z_{1} & =\mathrm{R}_{1}+\mathrm{j} \mathrm{X}_{\mathrm{L} 1} \\
Z_{2} & =\mathrm{R}_{2}+\mathrm{j}\left(\mathrm{X}_{\mathrm{L} 2}+\mathrm{X}_{\mathrm{m} 2}\right) \\
Z_{3} & =\mathrm{R}_{3}+\mathrm{j}\left(\mathrm{X}_{\mathrm{L}, 3}+\mathrm{X}_{\mathrm{m} 3}\right) \\
X_{23} & =\mathrm{j} \omega \mathrm{M}_{23} \\
X_{32} & =\mathrm{j} \omega \mathrm{M}_{32}^{\prime} \\
X^{\prime} & =j \omega L^{\prime} \\
\mathrm{K}_{\mathrm{b}} & =\text { bridge constant }
\end{aligned}
$$

All dashed values are referred to the MC circuit. Equations 3 to 6 are represented in matrix form as;

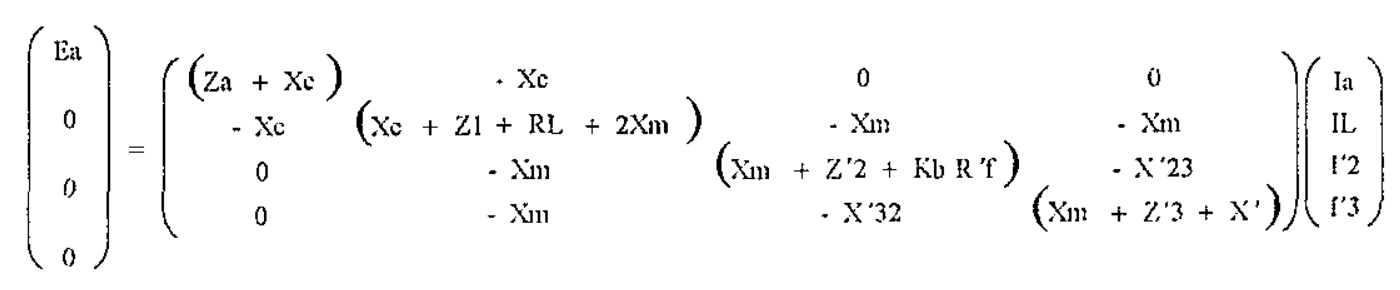

Solving the above matix yields the currents $I_{\mathfrak{a}}, I_{L}, I_{2}$ and $I_{3}$. The referred field current $\left(I_{f}^{\prime}\right)$ is also defined from equation (10). The field current $I_{f}$ is given by:

$$
I_{f}=\left(N_{M C} / N_{F C}\right) i_{\mathrm{r}}
$$

Where $\mathrm{N}_{\mathrm{MC}}$ and $\mathrm{N}_{\mathrm{EC}}$ are the turns number of $\mathrm{MC}$ and $\mathrm{EC}$ coils respectively .

4- the new operating point can be defined at the current $I_{r}$. Then the matrix is solved at this new operating point, yielding the corresponding currents.

5- the other performances such as load voltage, load power, input power, and efficiency are computed respectively as follows;

$$
V_{\mathrm{I},}=\mathrm{I}_{\mathrm{I}}, \mathrm{R}_{\mathrm{l}}
$$




$$
\begin{gathered}
P_{1}=V_{1} I_{1} \\
P_{i n}=E_{i} \quad I_{a} \cos (\varphi) \\
\eta=P_{L} / P_{i n} \quad \therefore:
\end{gathered}
$$

The above procedure is repeated for other load resistances and at different values of inductance $\mathrm{L}$. A computer program has been written to obtain the generator performance.

\section{Experimental Results and Discussion}

A $2.2 \mathrm{KW}, 220 \mathrm{~V}$ /phase, $4.6 \mathrm{~A}$ /phase, 4-pole, $50 \mathrm{~Hz}$ three phase slip-ring induction machine is operated as a synchronous generator. It is mechanically coupled to a $3 \mathrm{KW}$ d.c. motor as a prime mover. A 2.9 Ampere three phase tap-changing core type transformer is utilized as a voltage regulator. The number of turns mounted on each limb is chosen as 287 turn for the EC, 256 turn for the RC and 138 turn for the MC. A capacitor of $22 \mu \mathrm{F} /$ phase was found suitable for building-up voltage at no-load and at speed of 1500 r.p.m. A variable three -phase resistance is used for loading the generator.

Without capacitor, the generator performance characteristics are obtained as shown in Figs.5-8. The generator can not build-up voltage at no load since the field current is zero. Figure 5 shows that the generator starts building-up voltage of about $140 \mathrm{~V}$ at load current of $0.8 \mathrm{~A}$, when the inductance $\mathrm{L}=0$ (the regulating coil is short circuited). The same voltage is also obtained at load current of $1.2 \mathrm{~A}$, when the inductance $\mathrm{L}=50 \mathrm{mH}$. The field current increases as the load current increases or the inductance $\mathrm{L}$ decreases as illustrated in Fig.6. This in turns increases the load voltage against load current. The corresponding load power and efficiency are shown in Figs.7 and 8 respectively. Higher efficiencies are obtained as the inductance $\mathrm{L}$ decreases.

Figures 9-14 show the measured and computed characteristics when a capacitor of $22 \mu \mathrm{F}$ / phase is connected at the generator terminals. At no- load, the generator builds- up voltage of about $230 \mathrm{~V} /$ phase as shown in Fig.9. Depending on the inductance value, the load voltage against load current takes different shapes. If $\mathrm{L}=0.0$, the over compound characteristic is obtained where the load voltage increases more than the no-load voltage. At $\mathrm{L}=50 \mathrm{mH}$, the increasing rate in the load voltage decreases and then the flat compound characteristic is obtained. Increasing the value of $L$ gives the under compound characteristics, where the load voltage decreases below the no-load voltage. The corresponding capacitor voltage ,field current, armature current, load power and efficiency are illustrated in Figs.10-14 respectively. It can be noticed that, sensitive voltage control can be obtained by adjusting the inductance L. Efficiency of about $82 \%$ is obtained, achieving low power loss. 


\section{Conclusion}

This paper presents the magnetic voltage regulator(MVR) as a new technique for self-regulated self-excited three phase synchronous generator. The field excitation is controiled automatically with the load current. For a wide range of excitation control, the flux in the magnetic core of the MVR is oriented by controlling the current in the regulating coil. Thus the load voltage can be widely controlled and the compound characteristics (over,flat and under) are obtained. Building-up voltage at no load is achieved by using a suitable threephase capacitor at the generator terminals.

The proposed MVR is simple in construction, cheap and reliable compared with the conventional self-excitation system which utilizes current and potential transformers. The theoretical analysis based on the derived equivalent circuit model is given. Experimental set-up is built and the measured results are in good agreement with those obtained theoretically.

\section{References}

1) G.A.Ghoneem, A.El-Khatib and F.E. Abdel-Kader, "Analysis of brushless and self-excited single phase generator.", Proceeding of Jordan international power system conference, October 4-6,1993(JIPSC-93), ,pp. $136-141$.

2) G.A.Ghoneem, A.El-Khatib and F.E. Abdel-Kader,"Choosing the proper angle of output winding in the brush-less self-excited single phase alternator". Al-Azhar Engineering third International conference, Dec.1821,1993 (AEIC'93) Vol. 5, pp. 34-54.

3) G.A.Ghoneem,A.El-Khatib and F.E. Abdel-Kader, "Excitation improvement of brush-less self-excited single phase synchronous generator" . Al-Azhar Engineering third International conference, Dec. 1821,1993 (AEIC'93) Vol. 5, pp. 138-147.

4) S.Nonaka and Muta, "Characteristics of brush-less self-excited single phase synchronous generator ". Electrical Engineering in Japan, Vol. 91, No.4, pp.41-51, April 1971.

5) B.J.Chalmers, R.M. Magireanu and J. Hindmarsh, "General principle for brushless synchronous machines and its application in an inverter-fed drive . Proc. IEE, Vol. 119, No.11, Nov. 1972, pp. 1641- 1642.

6) Meng Chauanfu, etc "Test and analysis on the voltage wave form of single-phase salient pole synchronous generator" Proc. (Part 1), 
International conference on evolution and modern Aspects of synchronous machines, Zurich, Switzerland 27-29 August 1991.

7) S.Nonaka, "A New brush-less excitation method for three-phase synchronous generator.", International Aegean Conference on Electrical Machines and Power electronics. Vol. 2/2, 5-7, June 1995, Kusadasi; Turkey, pp.474-496.

8) F.Shibata and T.Kohrin, "A brush-less, self-excited poly-phase synchronous generator". IEEE Trans. On Power App. and systems, Vol. PAS-102, No. 8, August 1983, pp. 2413 - 2419.

9) S. Nonaka and K. Kesamaru, "Brush-less three-phase synchronous generator without exciter". Elect. Eng. In Japan, Vol. 105, No. 6, 1985, pp.91-97.

10) K.Inoue, H.Yamashita, E. Nakamae and T. Fujikawa, "Brush-less selfexcited three-phase synchronous generator without exciter". Elect. Eng. In Japan, Vol. 113, No. 8, Dec. 1993, pp. $101-115$.

11) F. Shibata and N. Naoe, "Characteristics of a brush-less and exciter-less three-phase synchronous generator with DC exciting system". Elect. Eng. In Japan, Vol. 113, No. 2, April 1993, pp. $80-90$.

12) F.Shibata and N.Naoe, "Brush-less and exciter-less, self-excited threephase synchronous generator having an armature winding supplied with DC exciting current from a voltage-current transformer". Conf. Record of the 24 $4^{\text {th }}$ IEEE Industry App. Society Annual Meeting, Pt. 1, 1989, Piscataway, NJ, USA, pp. $301-307$.

13) T.Fukami, T.Kawai and T.Miyamoto,"Self-regulated self-excited brushless three-phase synchronous generator". Elect. Eng. In Japan, Vol. 117 , No. 2, Aug. 1996, pp. $18-28$.

14) A.M. El-Khatib, G.A.Ghoneem, S.A.Kalilah and F.E.Abdel-Kader, "New operation of synchronous motor with series excitation". Sixth Middle-East Power System Conference (MEPCON' 98), Mansoura, Egypt, Dec. $15-17,1998$, pp. $412-418$.

15) S.A.Kalilah, "Capacitor series excitation for improved performance of the three phase synchronous generator." International conference on electrical machine 28-30,August 2000 (ICEM'2000), Espoo, Filand.

16) Fathy Elsayed Abdel-Kader, "The reciprocated flux voltage regulator" Seventh international middle east power systems conference (MEPCON'2000), March 28-30, 2000, pp.127 


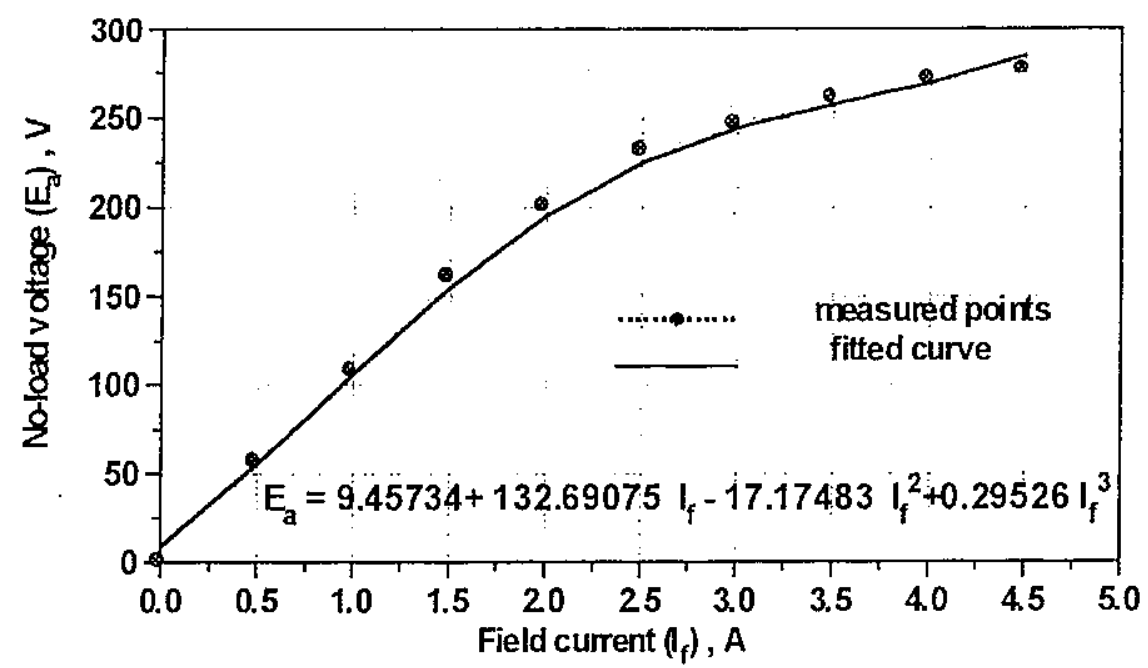

Fig.3 The magnitization curve of the generator

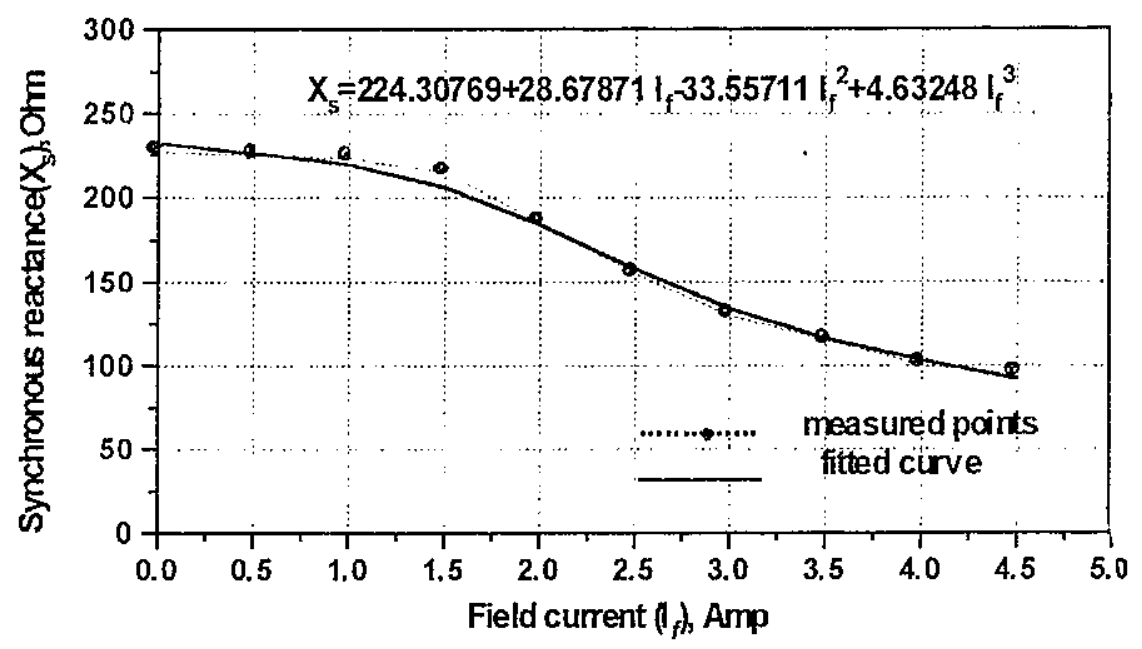

Fig.4 The synchronous reactance with field current

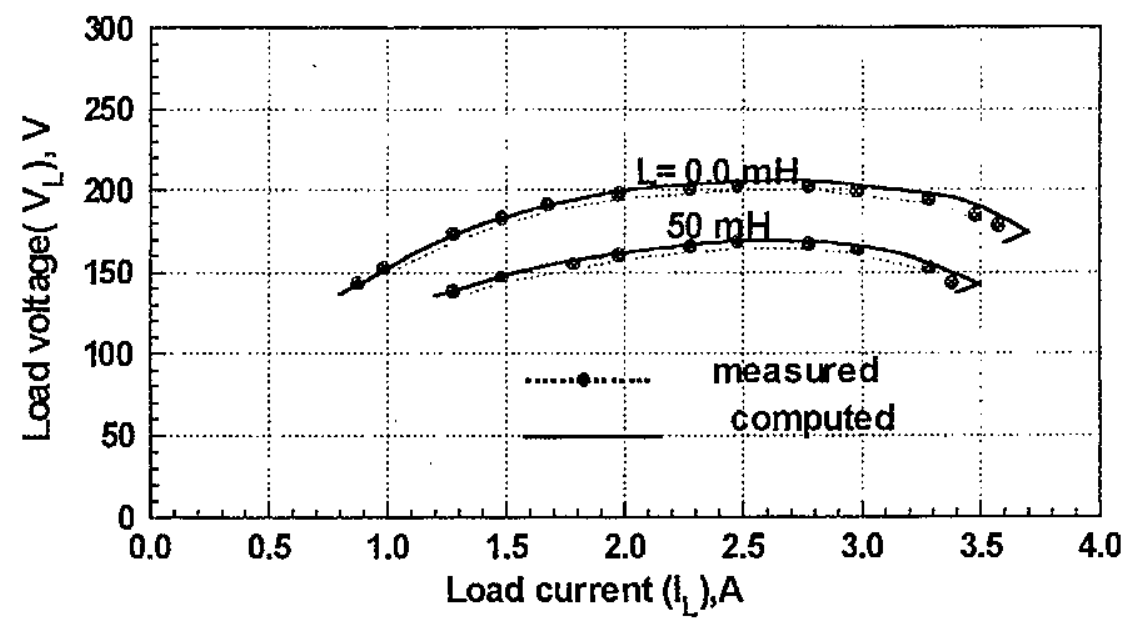

Fig.5 Load voltage against load current $(C=0.0 \mu$ P) 


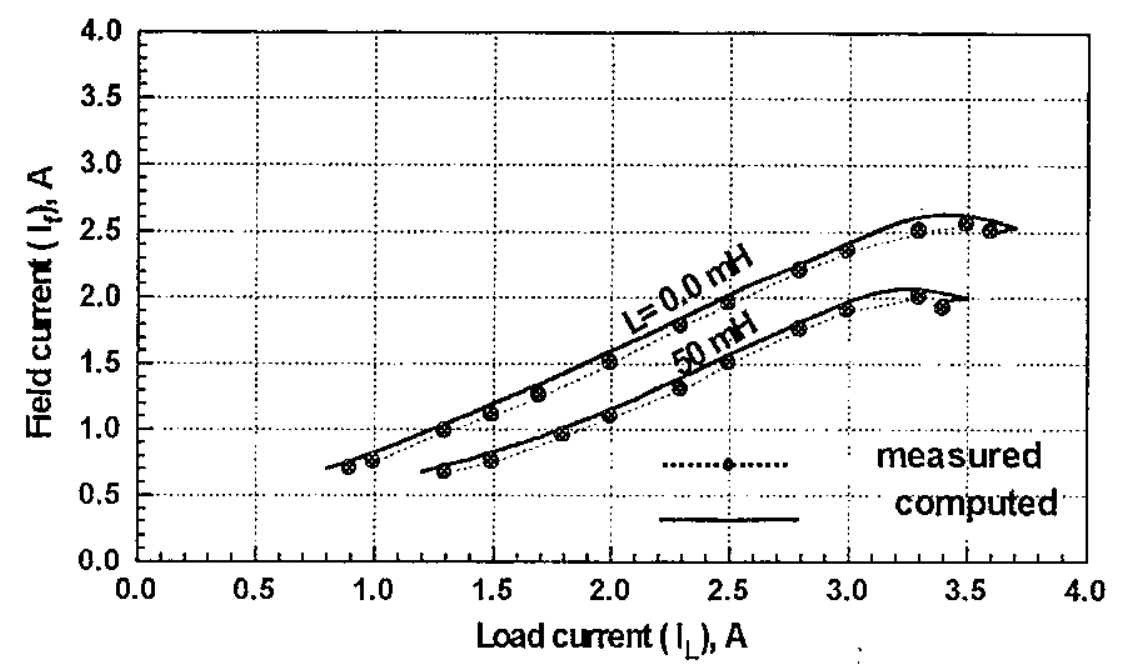

Fig. 6 Field current against load current $(C=0.0 \mu \mathrm{F})$

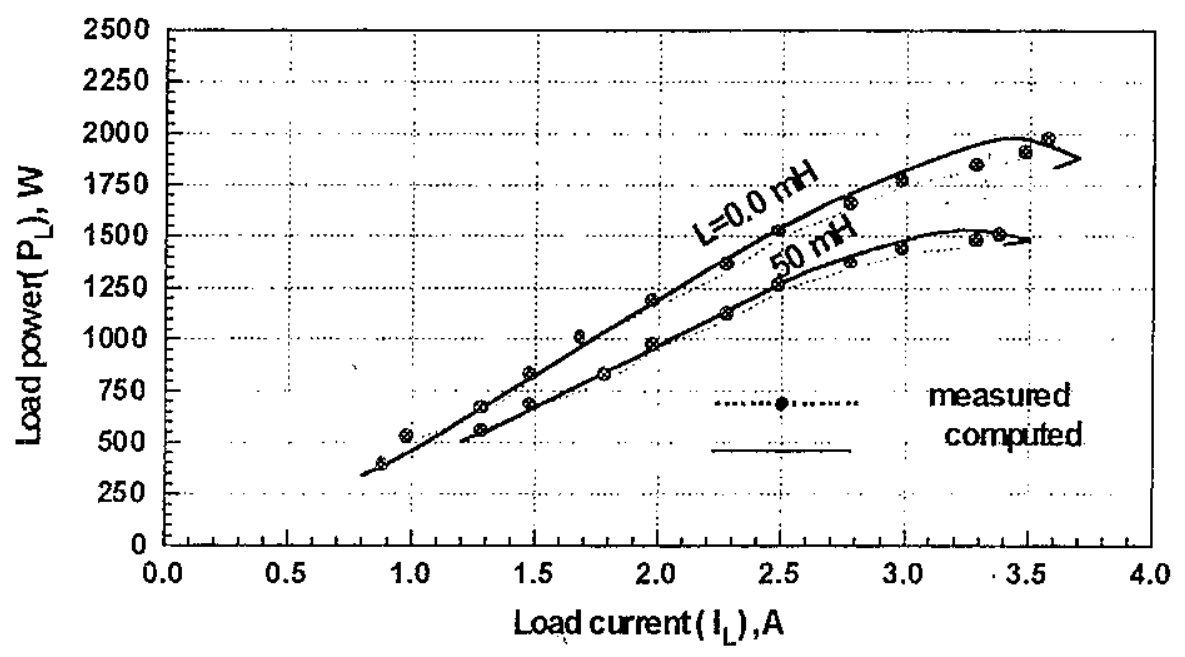

Fig. 7 Load power aga inst load current $(C=0.0 \mu \mathrm{F})$

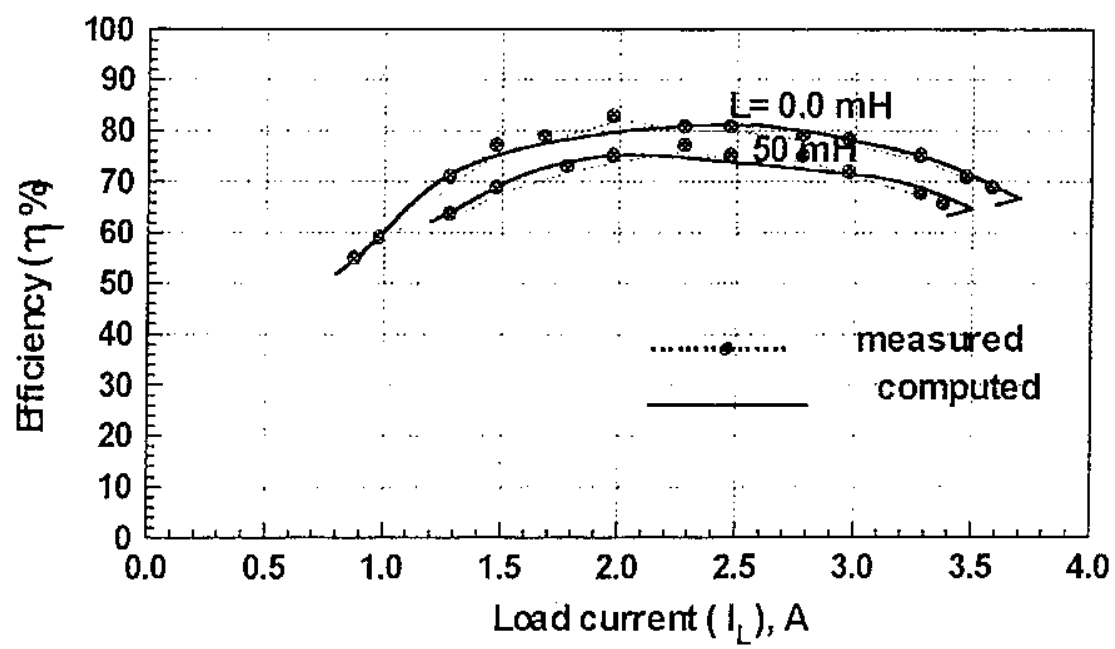

Fig. 8 Efficiency aga inst load current $(C=0.0 \mu \mathrm{F})$ 


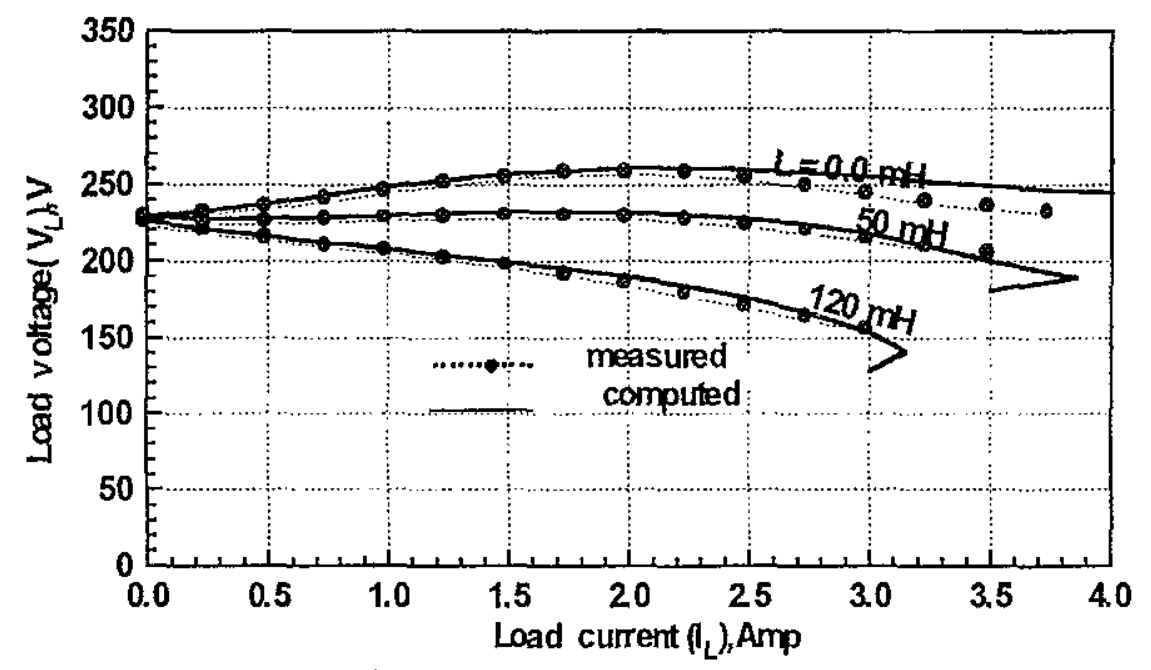

Fig.9 Load voltage against load current $(C=22 \mu \mathrm{F})$

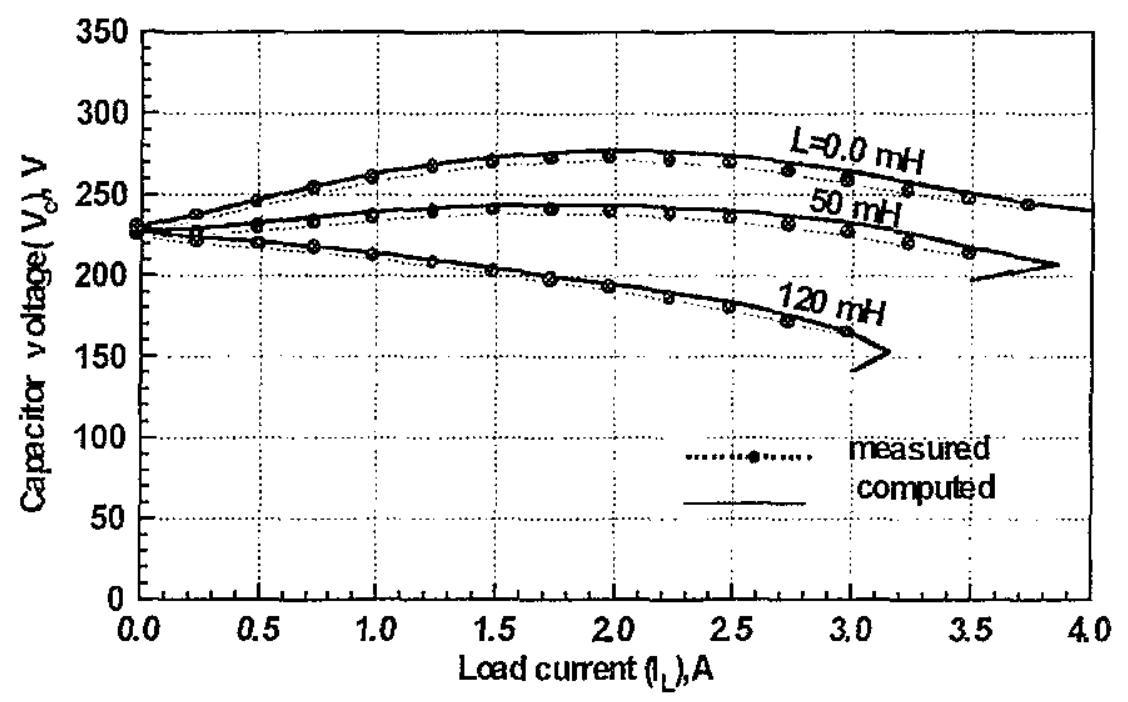

Fig.10 Capacitor voltage against load current $(C=22 \mu \mathrm{F})$

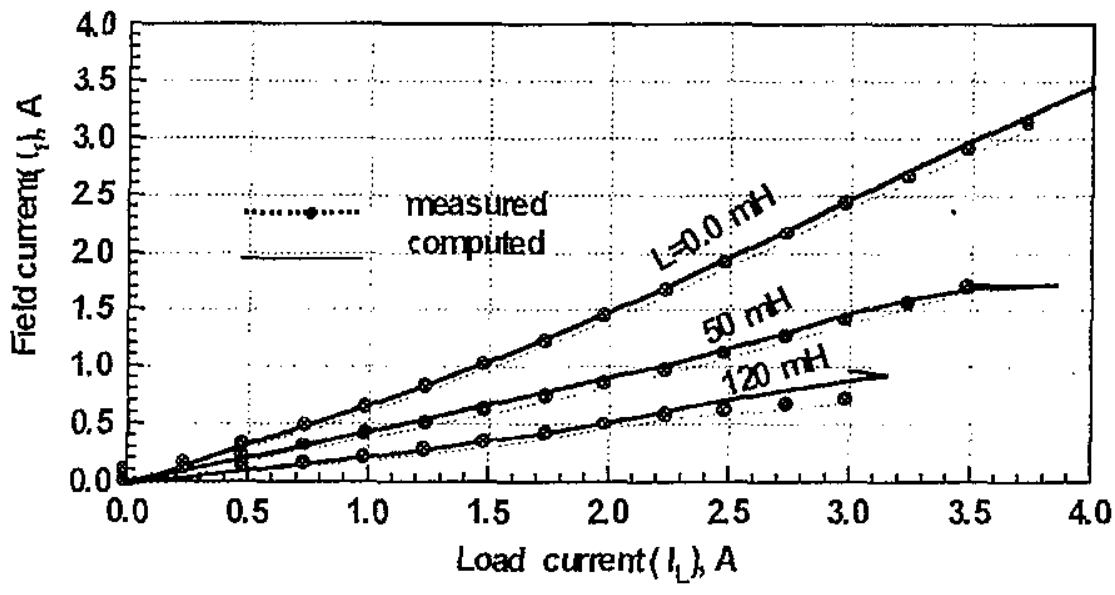

Fig.11 Field current against load current ( $C=22 \mu \mathrm{F}$ ) 


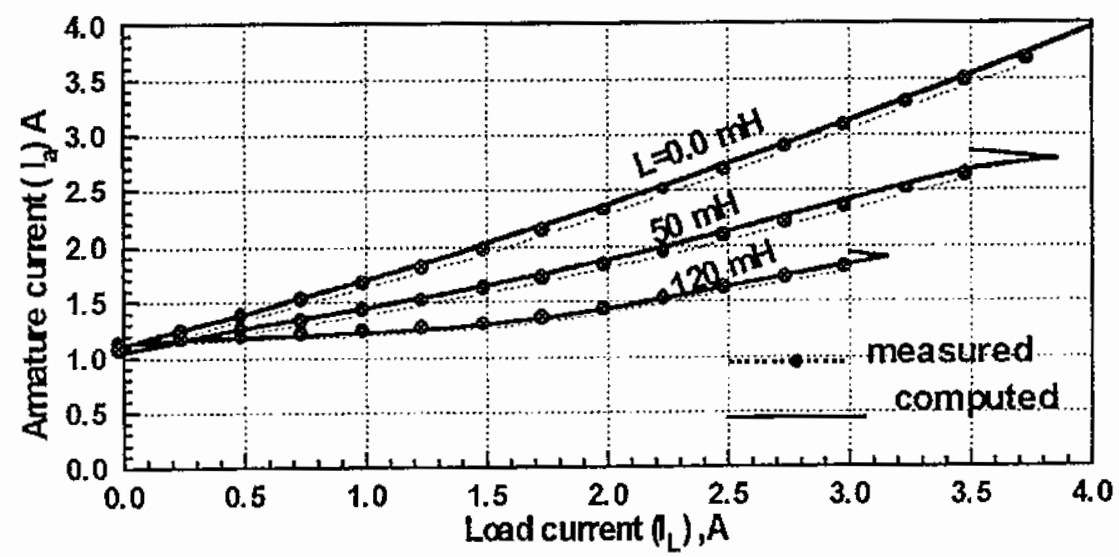

Fig.12 The armature current against load current ( $C=22 \mu \mathrm{F}$ )

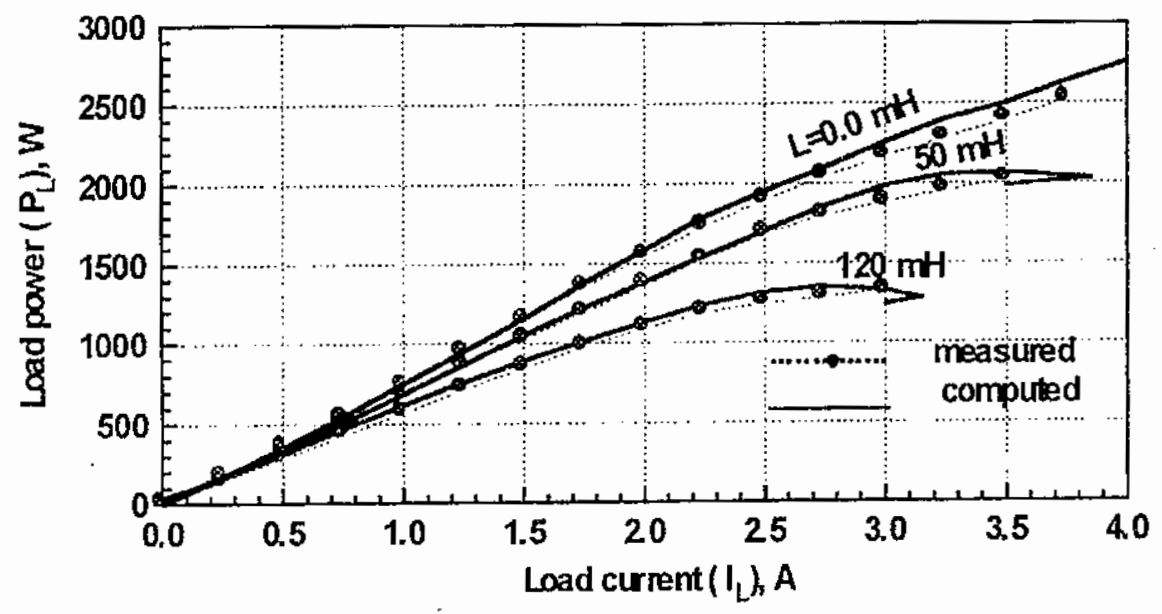

Fig.13 Load power against load current ( $C=22 \mu \mathrm{F}$ )

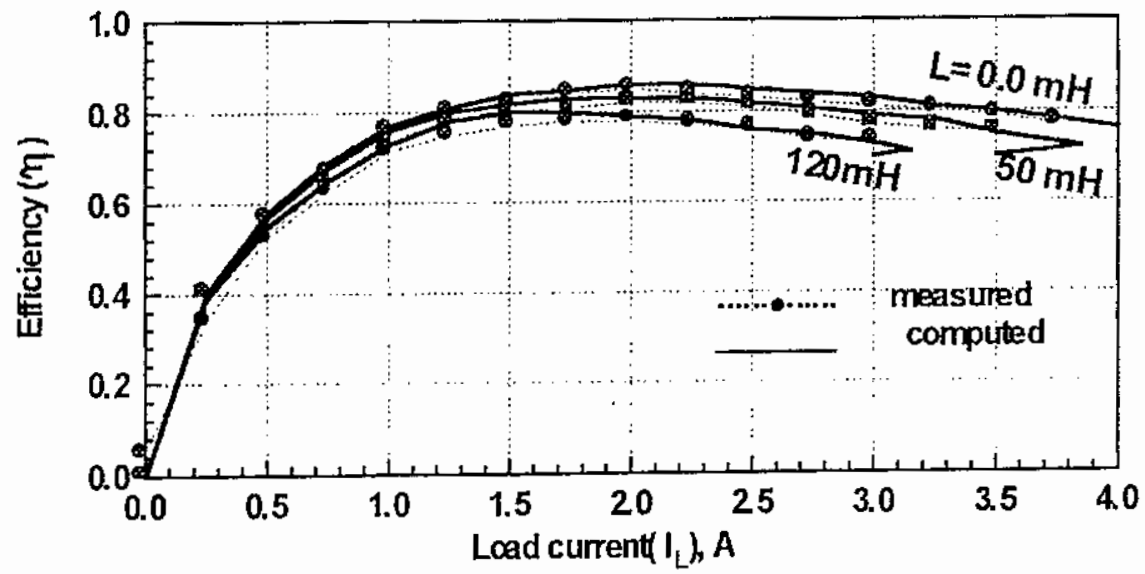

Fig.14 Efficiency against load current ( $C=22 \mu \mathrm{f}$ ) 


\section{$8 \mathrm{~S}$}

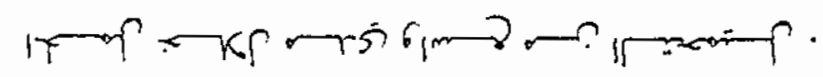

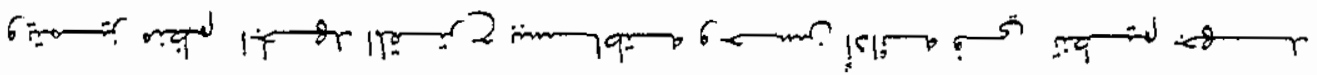

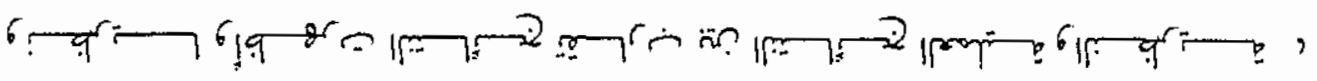

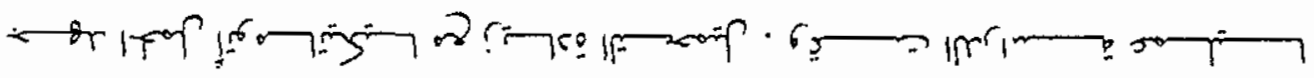

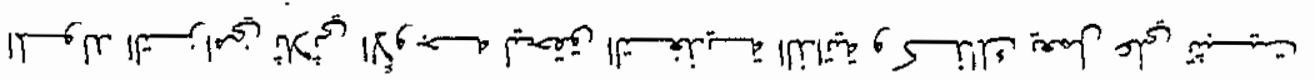
$\Pi$ ח

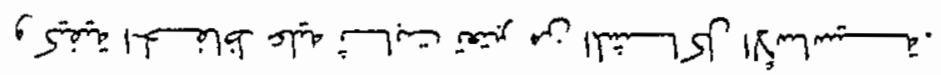

por

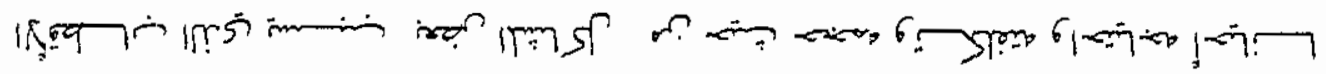

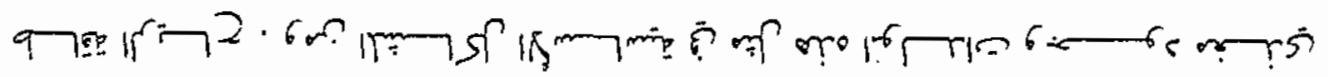

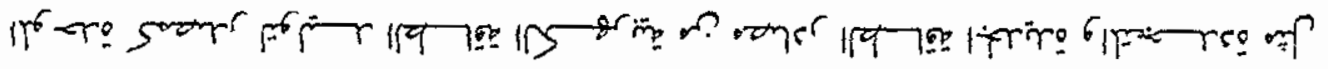

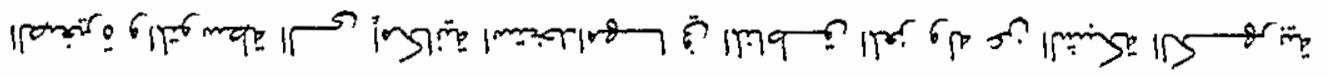

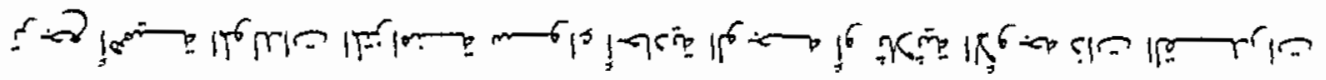

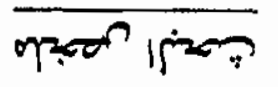

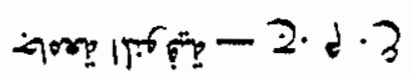

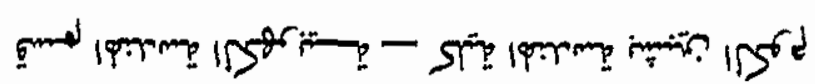

$6 \%$ لهن

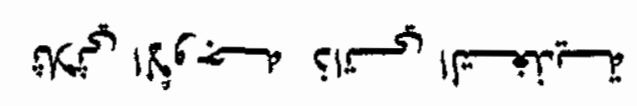

o 